\title{
MERANCANG PERUBAHAN DI SEKOLAH UNTUK MENJADI SEKOLAH YANG MEMPROMOSIKAN KESEHATAN MENTAL
}

\author{
Usmi Karyani \\ Fakultas Psikologi Universitas Muhammadiyah Surakarta \\ uk257@ums.ac.id
}

\begin{abstract}
In recent decades occurred global concern for mental health problems in children and adolescents. World Health Organization (WHO) gives mandate to all countries to involve schools as the main setting for health promotion for children and adolescents. Generally, the success of health promotion assessed from the quality of the program concerning its effectiveness, and the level of sustainability of the program. Many school-based mental health promotion programs proved effective for tackling mental health problems, but low level of sustainability. This is because the school is not considered mental health as primary business. To improve the sustainability of the program will require institutionalization of mental health promotion programs that enable every school as a school that promotes mental health. This article contains a review of the literature to find the idea of preparing a school that promotes mental health. Review will be focused on: (1) how to design a school that promotes mental health for children and adolescents, and (2) how to design the organizational structure and human resource development needed to increase efektitas mental health promotion program in schools.
\end{abstract}

Keywords: design organization, school, mental health, promotion

\begin{abstract}
Abstraksi. Dalam beberapa dekade terakhir ini terjadi keprihatinan secara global terhadap banyaknya masalah kesehatan mental pada anak dan remaja. WHO memberikan mandat kepada semua negara untuk menjadikan sekolah sebagai tumpuan untuk mempromosikan kesehatan mental bagi anak dan remaja. Keberhasilan program promosi kesehatan dinilai dari dua hal, yakni kualitas program (menyangkut keefektififannya) dan tingkat keberlanjutan program. Banyak program promosi kesehatan mental berbasis sekolah efektif mengatasi masalah kesehatan mental,namun tingkat keberlanjutannya rendah, karena sekolah tidak menganggap kesehatan mental sebagai bisnis utamanya. Untuk meningkatkan keberlanjutan program maka diperlukan institusionalisasi program promosi kesehatan mental yang memampukan setiap sekolah sebagai sekolah yang mempromosikan kesehatan mental. Artikel ini merupakan kajian literatur untuk menemukan gagasan mempersiapkan sekolah yang mempromosikan kesehatan mental. Tulisan ini akan difokuskan pada: (1) bagaimana merancang sekolah yang mempromosikan kesehatan mental bagi anak dan remaja, dan (2) bagaimana rancangan struktur organisasi dan pengembangan SDM yang diperlukan untuk meningkatkan efektitas program promosi kesehatan mental di sekolah.
\end{abstract}

Kata Kunci: rancangan organisasi, sekolah, kesehatan mental, promosi

\section{PENDAHULUAN}

Kesehatan menjadi tujuan penting bagi seluruh masyarakat dunia mengingat dampaknya terhadap keberfungsian semua aspek kehidupan. Kesehatan oleh WHO (2004) diartikan sebagai keadaan sempurna baik fisik, mental, kesejahteraan sosial, dan bukan hanya bebas dari penyakit atau kecacatan. Dengan demikian, jelas bahwa kesehatan mental merupakan bagian tak terpisahkan dari pengertian kesehatan.

Kesehatan mental bukan sekedar ketiadaan simptom-symptom psikopatologi namun tercapainya keadaan well-being di mana individu menyadari kemampuannya, mampu mengatasi situasi menekan dalam kehidupannya, mampu bekerja secara produktif dan bermanfaat, serta mampu 
berkontribusi dalam masyarakatnya (WHO, 2004). Dalam pengertian tersebut maka WHO menggunakan perspektif positif dalam mengartikan kesehatan mental, dalam hal ini kesehatan mental dipandang sebagai dasar untuk tercapainya well-being dan keefektifan fungsi seseorang sebagai individu dan sebagai bagian dari masyarakat.

Isu kesehatan mental yang marak beberapa dekade terakhirini adalah banyaknya masalah kesehatan mental pada anak dan remaja. WHO (2004) mengemukakan bahwa $20 \%$ dari remaja berusia 18 tahun ke bawah mengalami masalah dalam perkembangan, masalah emosional dan perilaku. Dari jumlah tersebut yang mengalami gangguan mental adalah 1 per 8 anak, sedangkan pada populasi miskin 1 per 5 anak. WHO (2013) memperkirakan beberapa tahun mendatang masalah kesehatan mental dan psikopatologi pada anak dan remaja akan menjadi salah satu dari lima masalah utama yang menyebabkan disabilitas, morbiditas, atau bahkan mortalitas. Tingginya populasi yang mengalami masalah kesehatan mental dan psikopatologi akan berdampak terhadap beban ekonomi. WHO (2003) saat ini memperkirakan 2,5\% - 4\% dari total anggaran suatu negara dialokasikan untuk menangani masalah tersebut.

Guna mengendalikan laju terjadinya masalah kesehatan mental dan psikopatologi, maka ditekankan kembali pentingnya upaya promosi kesehatan mental di berbagai setting (Williams, Saxena, \& McQueen, 2005). Untuk mengatasi masalah kesehatan mental pada anak dan remaja, sekolah menjadi tumpuan harapan (Wyn, Cahill, Holdsworth, Rowling, \& Carson, 2000). Sekolah perlu didesain sebagai sekolah yang mempromosikan kesehatan mental kalangan anak dan remaja (WHO, 2005). Hal tersebut memperjelas bahwa sekolah merupakan public health setting (Miller, Nickerson, \& Jimerson, 2009).

Keunggulan sekolah sebagai setting untuk promosi kesehatan mental antara lain: (1) Sekolah merupakan lembaga yang dengan sengaja berdiri untuk meningkatkan kualitas sumber daya manusia, (2) Anak usia sekolah (6 - 18 tahun) mempunyai proporsi paling tinggi dibanding dengan kelompok usia lainnya, (3). Hampir semua anak dan remaja menjalani kegiatannya di sekolah (minimal 4- 7 jam perhari) selama minimal 12 tahun ,dan (4). Anak-anak dan remaja yang ada di sekolah menjadi lebih mudah dijangkau karena berada dalam satu setting (Wyn, Cahill, Holdsworth, Rowling, \& Carson, 2000; Aggleton, Dennison, \& Warwick, 2010; Atkinson \& Hornby, 2002; Spotlight, 2012, Notoatmodjo, 2010; Miller, Nickerson, \& Jimerson, 2009).

Keberhasilan program promosi kesehatan mental pada dasarnya dapat dilihat dari kualitas impelementasinya (efektif atau tidak efektif) dan tingkat keberlanjutannya (Adams, 2007). Berbagai kajian menunjukkan bahwa promosi kesehatan berbasis sekolah efektif untuk meningkatkan kesehatan mental dan well-being (Clarke \& Barry, 2010; Weare, 2013), dan prestasi akademik (Dix, Slee, Lawson, \& Keeves, 2012). Keberlanjutannya sulit dicapai. Faktor utamanya antara lain upaya promosi kesehatan di sekolah lebih banyak yang berbasis individu dengan memberikan tritmen tertentu pada siswa yang bermasalah, atau berbasis kelas dengan menggunakan penyuluhan/ pendidikan kesehatan selain itu pencapaian derajat kesehatan mental bukan menjadi bisnis utama sekolah (Rowling, 2009). Oleh karena itu promosi kesehatan mental berbasis sekolah sangat penting sebagai strategi yang mengubah dari penanganan kesehatan mental 
yang bersifat individual ke pendekatan organisasi, dengan demikian efektifitas dan keberlanjutan program promosi kesehatan berbasis sekolah dapat ditingkatkan (Samdal \& Rowling, 2010).

Dalam konsep WHO (2005) promosi kesehatan mental dengan menggunakan pendekatan sistem/organisasi diistilahkan dengan whole school approach. Dalam hal ini promosi kesehatan mental di sekolah bukan hanya menangani siswa yang mengalami masalah kesehatan mental dan psikopatologi, namun meningkatkan kapasitas positif siswa dan seluruh guru dan staf sekolah serta orang tua, dan melibatkan pihak-pihak terkait. Bukan hanya memberikan penanganan pada siswa yang bermasalah namun juga menyusun kebijakan yang mampu memfasilitasi seluruh komunitas sekolah untuk meningkatkan kesehatan mental mereka. Oleh karena itu, sekolah perlu mempromosikan kesehatan mental dengan cara didisain sebagai "institusi positif" yang mendorong tercapainya kesehatan mental dan well-being seluruh komunitas sekolah.

Artikel ini merupakan kajian literatur mengenai bagaimana mendesain sekolah agar mampu berfungsi sebagai sekolah yang mempromosikan kesehatan, termasuk diantaranya kesehatan mental anak dan remaja.

\section{Sekolah yang Mempromosikan Kese- hatan Mental}

The Health Promotion School (HPS) merupakan program promosi kesehatan dalam setting sekolah yang secara formal dikembangkan oleh WHO sebagai tindak lanjut dariOttawa Charter tahun 1986. Melalui HPS diharapkan sekolah memiliki peran signifikan dalam membentuk generasi yang akan datang sebagai generasi yang terdidik dan sehat (WHO, 1998). Sejak diluncurkan pertama, HPS telah diimplemantasikan di 37 negara dengan derajat keberhasilan yang bervariasi (Leger, 1999). Mengacu pada pengertian kesehatan dari WHO (2001) maka konsep HPS meliputi promosi kesehatan fisik, mental, dan social well-being.

Promosi kesehatan, dirumuskan oleh WHO sebagai proses memampukan masyarakat untuk memelihara dan meningkatkan kesehatan mereka secara sempurna baik fisik, mental dan sosial-wellbeing. Individu atau kelompok harus dapat mengenali dan mewujudkan aspirasinya, memenuhi kebutuhannya, serta mampu mengubah atau mengatasi lingkungannya. (WHO, 1998). Sekolah yang mempromosilan kesehatan memiliki karakteristik "healthy setting, for living, learning, and working" Sekolah yang mempromosikan kesehatan merupakan sekolah yang berkomitmen melakukan aksi untuk meningkatkan derajat kesehatan dan wellbing di komunitas sekolah (WHO, 1998). Untuk mendukung pencapaian tujuan tersebut maka sekolah perlu mengintegrasikan upaya promosi kesehatan melalui kurikulum, pengembangan etos sekolah dan lingkungan yang mendukung kesehatan dengan melibatkan orangtua siswa dan komunitas di sekitar sekolah (WHO, 1998). Dengan kata lain, dalam HPS terdapat tiga elemen dasar yang saling berhubungan, yakni: (1) organisasi, etos dan lingkungan sekolah; (2) Kurikulum, pengajaran, dan pembelajaran; dan (3) kerjasama dan pelayanan.

Apabila digambarkan maka konsep HPS sebagaimana tampak pada gambar 1 . 


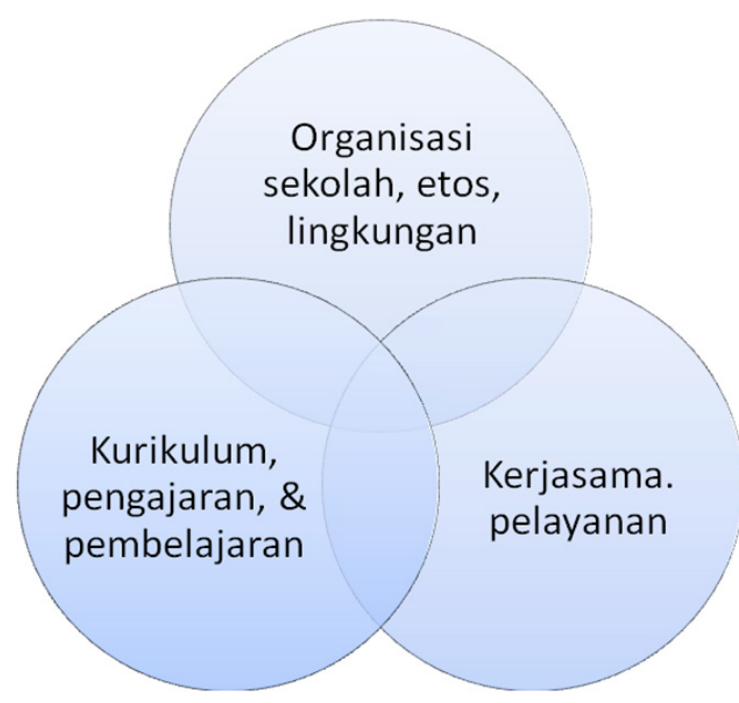

Gambar 1. Konsep HPS

Di Indonesia tampaknya HPS diupayakan melalui penguatan program Usaha Kesehatan Sekolah (UKS). Guna meningkatkan kinerja UKS maka pemerintah pada tahun 1984 mengeluarkan SKB empat kementerian, Pendidikan dan Kebudayaan, Kesehatan, Agama, dan Dalam Negeri, yang mengatur tentang Pokok Kebijaksanaan Pembinaan dan Pengembangan Usaha Kesehatan Sekolah. Kemudian tahun 2003 diubah lagi dengan keluarnya SKB empat kementerian, tentang Pembinaan dan Pengembangan Usaha Kesehatan Sekolah. Dalam SKB tersebut ditekankan bahwa Usaha Kesehatan Sekolah (UKS) ditujukan untuk meningkatkan mutu pendidikan dan prestasi belajar peserta didik dengan meningkatkan perilaku hidup bersih dan sehat dan derajat kesehatan peserta didik maupun warga belajar serta menciptakan lingkungan yang sehat, sehingga memungkinkan pertumbuhan dan perkembangan yang harmonis dan optimal dalam rangka pembentukan manusia Indonesia seutuhnya.

Usaha

Kesehatan

Sekolah

diselenggarakan oleh semua sekolah mulai dari Taman Kanak-kanak hingga Sekolah Menengah Atas, baik umum maupun kejuruan, maupun untuk Sekolah Luar Biasa. Dengan sasaran siswa, guru/pamong belajar, pengelola sekolah, pengelola kesehatan dan masyarakat. Dengan SKB tersebut UKS diharapkan mampu mencapai kinerjanya dengan baik melalui kerjasama sekolah dengan pemangku kepentingan terkait.

Dalam menjalankan tugas dan fungsinya UKS menggunakan Trias UKS, yang terdiri dari: (a) penciptaan lingkungan sekolah yang sehat; (b) pemeliharaan dan pelayanan di sekolah; dan (c) upaya pendidikan yang berkesinambungan. Kementerian Pendidikan dan Kebudayaan (2012) mengemukakan bahwa efektifitas UKS dinilai dari enam unsur berikut, sebagai pengejawantahan dari Trias UKS: (1). Perubahan tingkat pengetahuan pada umumnya yang berhubungan dengan kesehatankhususnya;(2). Perubahan sikap dan penghayatan terhadap prinsip dan pola hidup bersih dan sehat; (3) Perubahan tingkah laku kebiasaan hidup sehari-hari dan keterampilan dalam melaksanakan prinsip pola hidup bersih dan sehat termasuk peningkatan daya tangkal terhadap pengaruh buruk dari kebiasaan merokok, penyalahgunaan narkoba, serta kepekaan terhadap kebersihan lingkungan; (4) Kemampuan hidup sehat dan derajat kesehatan yang telah terjadi pada peserta didik karena adanya pelayanan kesehatan di sekolah/madrasah; (5) Perubahan keadaan lingkungan khususnya lingkungan sekolah/ madrasah dan lingkungan tempat tinggal yang meliputi, tingkat kebersihan, sanitasi, keindahan, keamanan, ketertiban dan sebagainya; dan (6) Tingkat keberhasilan maupun ketidakberhasilan kegiatan pembinaan dan pengelolaan program UKS.

$$
\text { Capaian peningkatan derajat }
$$
kesehatan melalui UKS tampaknya belum menunjukkan hasil yang memuaskan atau belum sesuai dengan yang diharapkan. Kementerian Pendidikan dan Kebudayaan 
(2012) memberikan penilaian tentang kinerja UKS antara lain : (1) Prinsip hidup sehat dan derajat kesehatan peserta didik belum mencapai tingkat yang diharapkan; (2) mutu penyelenggaraan, ketenagaan dan sarana prasarana belum seimbang dengan usaha pencapaian tujuan UKS; (3) Perilaku hidup bersih dan sehat belum mencapai tingkat yang diharapkan, di samping itu ancaman penyakit terhadap peserta didik masih tinggi dengan adanya penyakit endemis dan kekurangan gizi; (4) Masalah kesehatan yang menimpa peserta didik meliputi: sanitasi dasar yang memenuhi syarat kesehatan, meningkatnya pengguna narkoba di kalangan remaja, meningkatnya HIV/AIDS melalui hubungan seksual, kurangnya perilaku Hidup Bersih dan Sehat seperti tampak pada masih tingginya diare, cacingan, gigi berlubang dan lain-lain; (5) masalah sumber daya manusia, seperi: kurangnya guru yang mengajar pendidikan kesehatan/guru yang menangani UKS; kurangnya kader Kesehatan Sekolah perlu dilatih dalam bidang kesehatan (pendidikan dan pelayanan); (6) Terbatasnya sarana dan prasarana UKS, seperti: Pengadaan UKS kit, ruang UKS, media seperti poster, leaflet, lembar balik, dan lain-lain; pengadaan buku pencatatan dan pelaporan; (7) Kurangnya koordinasi dan komitmen dalam pelaksanaan program UKS.

Bila dicermati maka program-program dalam Trias UKS mengacu pada program HPS yang dikemukakan oleh WHO) pada tahun 1998. Upaya pemerintah untuk menjadikan sekolah sebagai tempat yang sehat untuk tinggal, belajar, dan bekerja diupayakan melalui berbagai kebijakan sehingga saat ini hampir semua sekolah di Indonesia telah memiliki UKS. Namun demikian upaya tersebut belum menunjukkan hasil yang diharapkan. Bagaimana merancang sekolah agar berhasil menjadi sekolah yang sehat untuk tinggal, belajar, dan bekerja? Bagaimana merancang struktur organisasi sekolah agar kinerjanya efektif?

\section{Merancang Sekolah yang Mempromo- sikan Kesehatan Mental}

Sekolah telah lama menempatkan diri sebagai academic setting. Guna menakan laju masalah kesehatan mental, WHO memberikan mandat agar sekolah sebagai public health setting. Oleh karena itu, sekolah perlu mengubah "orientasi bisinisnya" yaitu akademik dan kesehatan, termasuk kesehatan mental. Perubahan tersebut bukan hal mudah mengingat sekolah tidak menganggap kesehatan mental sebagai bisnis utamanya (Adelman \& Taylor, 1999; Rowling (2009). Pandangan tersebut mengakibatkan kegiatankegiatan yang bertujuan untuk peningkatan kesehatan mental dianggap sebagai agenda tambahan yang tidak berhubungan dengan urusan pengajaran, sebagai akibatnya program-program yang dilakukan di sekolah, baik oleh akademisi maupun praktisi, tidak mampu bertahan lama (Adelman \& Taylor, 1999). Agar program-program kesehatan mental yang diimplementasikan di sekolah terus berlanjut maka penting untuk dilakukan pengembangan pada sistem sekolah secara sistematis (Adelman \& Taylor, 1999) dan melibatkan pengembangan organisasi (Samdal \& Rowling, 2010).

Pengembangan organisasi memiliki banyak pengertian. Cumming \& Worley (2008) merangkum sejumlah definisi pengembangan organisasi, dan menyimpulkan bahwa pengembangan organisasi ditandai oleh lima hal: (1) diterapkan untuk mengubah strategi, struktur, dan/atau proses dalam sistem; (2) didasarkan pada penerapan praktik dan pengetahuan ilmiah mengenai perilaku, baik konsep mikro seperti kepemimpinan, dinamika kelompok, dan design pekerjaan, 
maupun konsep makro seperti strategi, desain organisasi, dan relasi internasional; (3) menyangkut pengelolaan perubahan yang direncanakan; (4) meliputi desain, implementasi, dan reinforcement perubahan; (5) berorientasi untuk meningkatkan efektifitas organisasi. Berdasarkan uraian tersebut maka pengembangan organisasi merupakan bidang terapan yang seringkali difokuskan pada perubahan organisasi, dengan tujuan untuk meningkatkan efektifitas organisasi.

Kajian literatur yang dilakukan oleh Liopis \& Barry (2005) menunjukkan bahwa efektifitas promosi kesehatan mental dapat dicapai bila: (1) Program harus memiliki dasar teoretis. (2) Memiliki visi, misi, dan tujuan yang jelas yang dikembangkan bersama dengan komunitas dan mitramitranya sehingga transparan dan dipahami oleh semua pihak; (3) Ada dukungan dari mitra yang kompeten untuk memberikan pelatihan dan pendampingan penguatan kapasitas guru, tenaga kesehatan, dan lainlain; (4) Melakukan evaluasi dan monitoring dengan metode yang bermutu (sistematik dan ilmiah) untuk memastikan efektifitas intervensi; (5) Terdapat dukungan dari pimpinan dan dukungan infrastruktur. Penelitian lain menunjukkan bahwa budaya sekolah memiliki pengaruh kuat dalam proses perubahan sekolah (Heck \& Hallinger, 2009).

Adelman \& Taylor(1999) mengemukakan terdapat beberapa komponen yang dibutuhkan untuk mengubah sekolah sehingga mampu menjadi sekolah yang mempromosikan kesehatan mental. Komponen tersebut antara lain:

1) Perubahan kebijakan yang diterjemahkankedalampraktikseharihari. Komponen ini dapat dicapai melalui reformasi atau restrukturisasi organisasi, seperti misalnya alokasi sumber daya (keuangan, pegawai, waktu, peralatan, dan lain-lain) atau memodifikasi mekanisme organisasi yang telah ada saat ini. Hal-hal yang perlu dimodifikasi adalah: (a) governance (tatakelola); (b) planning (perencanaan); (c) koordinasi dan integrasi guna memastikan terjadinya fungsi yang kohesif; (d) kepemimpinan yang mampu memastikan program berjalan baik, yang mampu mengatasi kritik dari pemangku kepentingan dan menjadikannya masukan untuk bekerja dengan pemangku kepentingan secara efektif, terus berupaya memonitor dan memperbaiki dan (e) manajemen komunikasi dan informasi.

2) Perubahan sistem termasuk dalam pengalokasian anggaran. Komitmen terhadap komponen-komponen yang direstrukturisasi harus dinyatakan dalam kebijakan dan struktur organisasi guna memastikan kepemimpinan dan alokasi sumber daya yang efektif. Perubahan sistem diawali dengan menciptakan kesiapan untuk berubah, yang dapat dilakukan melalui: membangun kesadaran dan minat bersama untuk mengembangkan pendekatan yang komprehensif di sekolah yang ditujukan untuk mengatasi hambatan dalam belajar dan meningkatkan kesehatan; (b) memperkenalkan konsep-konsep dasar, khususnya elemen-elemen mendasar dari program kepada pemangku kepentingan yang sesuai; (c) menetapkan kerangka kebijakan yang menunjukkan bahwa mengintegrasikan pendekatan kom- 
prehensif dan sistematis (mengatasi hambatan belajar \& meningkatkan kesehatan mental) merupakan aktivitas utama dan esensial di sekolah; (d) penunjukkan pimpinan (yang berada di bawah top leader di sekolah) yang diyakini mampu mengimplementasikan kebijakan. Untuk memulai pengembangan organisasi maka selanjutnya adalah mempersiapkan hal-hal berikut: (a) menetapkanmekanismedan prosedur, seperti misalnya: pelatihan untuk para pengarah dan pimpinan agar mampu memandu proses reformasi di sekolah; (b) memformulasikan rencana secara spesifik (mulai startup dan phase-in); (c) menentukan dan pelatihan tim koordinasi sumber daya; (d) melakukan reorganisasi seluruh kegiatan yang ditujukan untuk mengatasi hambatan belajar dan meningkatkan kesehatan mental; (e) menjalin hubungan dengan pihak-pihak lain (sekolah lain, dinas pendidikan, sumber daya di masyarakat, dan lain-lain); (f) menetapkan sistemuntukmemastikan jaminan mutu, momentum untuk melakukan reformasi, dan mekanisme perbaikannya. Pengalaman di Amerika menunjukkan bahwa keberhasilan proses perubahan sekolah dapat ditingkatkan keberhasilannya dengan menggunakan fasilitator organisasi (organization facilitators) yang mendapat pelatihan untuk berperan sebagai agen perubahan di sekolah.

\section{Merancang Struktur Organisasi untuk Meningkatkan Efektifitas Sekolah}

Telah dikemukakan sebelumnya bahwa sekolah memiliki dua tugas yang terintegrasi, yakni mengatasi hambatan belajar dan meningkatkan derajat kesehatan siswa. Dua tugas utama tersebut perlu dikoordinasi dan dikendalikan agar sekolah dapat mencapai kinerja yang diharapkan.

Mintzberg (1980) mengemukakan bahwa cara pekerjaan dikoordinasi dan dikendalikan memberi pengaruh penting dalam mencapai efektifitas organisasi. Minzberg mengemukakan terdapat 5 tipologi struktur organisasi: simple structure (struktur sederhana), machine bureaucracy (birokrasi mekanis), professional bureaucracy (birokrasi professional), divisional form (bentuk devisi), dan adhocracy. Kelima tipologi tersebut dibangun berdasarkan lima elemen, yakni:

1) Lima bagian dasar organisasi : operating core; strategic apex; middle line; technostructur; dan support staff

2) Lima mekanisme dasar koordinasi: penyesuan mutual; pengawasan langsung; standardisasi proses kerja; outputs, dan keterampilan

3) Rancangan parameter: spesifikasi pekerjaan; formalisasi perilaku, pelatihan dan indoktrinasi; pengelompokan unit; ukuran unit; rencana tindakan dan sistem pengendalian kinerja, perangkat hubungan (misalnya penginintegrasian manager, tim, taks force, an struktur matriks); desentralisasi vertical, dan desentralisasi horizontal.

4) Faktor kontingensi: usia dan ukuran organisasi; sistem teknis, lingkungan, power (kekuasaan) 
Minzberg (1980) menjelaskan bahwa secara sederhana, sangat sentralis. Struktur kelima konfigurasi/tipologi tergantung ini diasosiasikan dengan lingkungan yang pada satu dari lima mekanisme koordinasi. dinamis dan pimpinan yang kuat dan biasanya Sebagai contoh bagian kunci dari struktur ditemukan pada organisasi kecil atau baru. organisasi sederhana terletak pada strategic Elemen-elemen dari lima konfigurasi struktur apex, dimana koordinasi dilakukan melalui supervisi langsung, struktur diuraikan organisasi yang dikemukakan Minzberg dapat dilihat pada Tabel 1.

Tabel 1. Elemen Lima Konfigurasi Struktur Organisasi Minzberg

\begin{tabular}{|c|c|c|c|c|c|}
\hline & Simple & $\begin{array}{c}\text { Machine } \\
\text { Bureaucracy }\end{array}$ & $\begin{array}{l}\text { Proffesional } \\
\text { Bureaucracy }\end{array}$ & Divisional Form & Adhocracy \\
\hline $\begin{array}{c}\text { Mekanisme } \\
\text { Koordinasi Kunci }\end{array}$ & $\begin{array}{l}\text { Supervisi } \\
\text { langsung }\end{array}$ & $\begin{array}{c}\text { Standardisasi } \\
\text { kerja }\end{array}$ & $\begin{array}{l}\text { Standardisadi } \\
\text { keterampilan }\end{array}$ & $\begin{array}{c}\text { Standardidasi } \\
\text { output }\end{array}$ & $\begin{array}{c}\text { Mutual } \\
\text { adjustment }\end{array}$ \\
\hline \multicolumn{6}{|l|}{ Disain parameter } \\
\hline \multicolumn{6}{|l|}{ Spesifikasi pekerjaan } \\
\hline - Horisontal & Rendah & Tinggi & Tinggi & Beberapa & Tinggi \\
\hline - $\quad$ Vertikal & Tinggi & Tinggi & Rendah & Beberapa & Rendah \\
\hline Pelatihan & Rendah & Rendah & Tinggi & Beberapa & Tinggi \\
\hline Indoktrinasi & Rendah & Rendah & Tinggi & $\begin{array}{l}\text { Beberapa } \\
\text { (manajer) }\end{array}$ & Bervariasi \\
\hline Formalisasi perilaku & Rendah & Tinggi & Rendah & $\begin{array}{l}\text { Tinggi (dalam } \\
\text { divisi) }\end{array}$ & Rendah \\
\hline Birokrasi/organik & Organik & Birokratik & Birokratik & Birokratik & Organik \\
\hline Pengelompokan & Fungsional & Fungsional & Fungsional dan pasar & Pasar & $\begin{array}{l}\text { Fungsional } \\
\text { dan Pasar }\end{array}$ \\
\hline Unit size & Besar & $\begin{array}{l}\text { Besar di bawah; } \\
\text { sempit di bagian } \\
\text { lain) }\end{array}$ & $\begin{array}{l}\text { Besar di bawah; } \\
\text { sempit di bagian lain) }\end{array}$ & Besar & Kecil \\
\hline $\begin{array}{l}\text { Perencanaan \& Sistem } \\
\text { Pengendalian }\end{array}$ & Kecil & $\begin{array}{l}\text { Perencanaan } \\
\text { tindakan }\end{array}$ & Kecil & $\begin{array}{l}\text { Pengendalian } \\
\text { Kinerja }\end{array}$ & $\begin{array}{l}\text { Terbatas } \\
\text { (misalnya } \\
\text { admin) }\end{array}$ \\
\hline Perangkat Penghubung & Sedikit & Sedikit & $\begin{array}{l}\text { Beberapa di } \\
\text { administrasi }\end{array}$ & Sedikit & $\begin{array}{l}\text { Banyak di } \\
\text { keseluruhan }\end{array}$ \\
\hline Desentralisasi & Sentralisasi & $\begin{array}{l}\text { Desentralisasi } \\
\text { horizontal terbatas }\end{array}$ & $\begin{array}{l}\text { Desentralisasi } \\
\text { horizontal dan } \\
\text { vertikal }\end{array}$ & $\begin{array}{l}\text { Desentralisasi } \\
\text { vertical terbatas }\end{array}$ & $\begin{array}{l}\text { Desentralisasi } \\
\text { selektif }\end{array}$ \\
\hline \multicolumn{6}{|l|}{ Faktor Kontingensi } \\
\hline Usia & Muda & Tua & Bervariasi & Tua & Muda \\
\hline Ukuran & Kecil & Besar & Bervariasi & Sangat besar & Bervariasi \\
\hline \multicolumn{6}{|l|}{ Sistem Teknis } \\
\hline - $\quad$ Regulasi & Rendah & Tinggi & Rendah & Tinggi & Rendah \\
\hline - $\quad$ Kompleksitas & Rendah & Rendah & Rendah & Rendah & $\begin{array}{l}\text { Rendah/ } \\
\text { Tinggi }\end{array}$ \\
\hline - Otomatisasi & Tidak ada & Tidak ada & Tidak ada & Tidak ada & Tidak ada \\
\hline \multicolumn{6}{|l|}{ Lingkungan } \\
\hline - $\quad$ Kompleksitas & Rendah & Rendah & Tinggi & Rendah & Tinggi \\
\hline - $\quad$ Dinamisasi & Tinggi & Rendah & Rendah & Rendah & Tinggi \\
\hline \multicolumn{6}{|l|}{ Power } \\
\hline - $\quad$ Fokus & $\begin{array}{l}\text { Strategic } \\
\text { apex }\end{array}$ & $\begin{array}{l}\text { Technostructure, } \\
\text { seringkali } \\
\text { eksterrnal }\end{array}$ & Operator professional & Middle line & Ahli \\
\hline - Fashionable & Tidak & Tidak & $\mathrm{Ya}$ & $\mathrm{Ya}$ & Terutama \\
\hline
\end{tabular}


Bila dicermati eleman-elemen dalam atau informal terletak pada operating core. konfigurasi yang dikemukakan oleh Para professional ini tidak hanya mengontrol Minzberg tersebut, maka sekolah yang pekerjaannya sendiri, namun mereka juga mempromosikan kesehatan condong untuk cenderung melakukan kontrol secara kolektif menggunakan Birokrasi Profesional. Struktur ini mengandalkan guru sebagai operating core yang memiliki keahlian dalam bidangnya. Kinerja akan banyak ditentukan bagaimana pada guru dalam menjalankan tugasnya. Salah satu kelebihan dari struktur ini adalah operating core memiliki otonomi sesuai dengan keahliannya sesuasi dengan standar keterampilan yang telah ditentukan oleh organisasi. Pada struktur ini desentralisasi terjadi secara vertikal maupun horizontal sehingga power formal pada aparat administratif. Manager pada lini tengah (dalam konteks sekolah adalah wakil kepala sekolah) harus memprofesionalkan diri, dan harus memberikan dukungan kepada para operator professional (guru). Pada tataran administratif, mereka harus memiliki mutual adjustment yang bagus dengan semua lini. Bila dikaitkan dengan konsep Health Promoting School yang dikemukakan oleh WHO, maka desain struktur sekolah dapat dibentuk sebagai berikut:

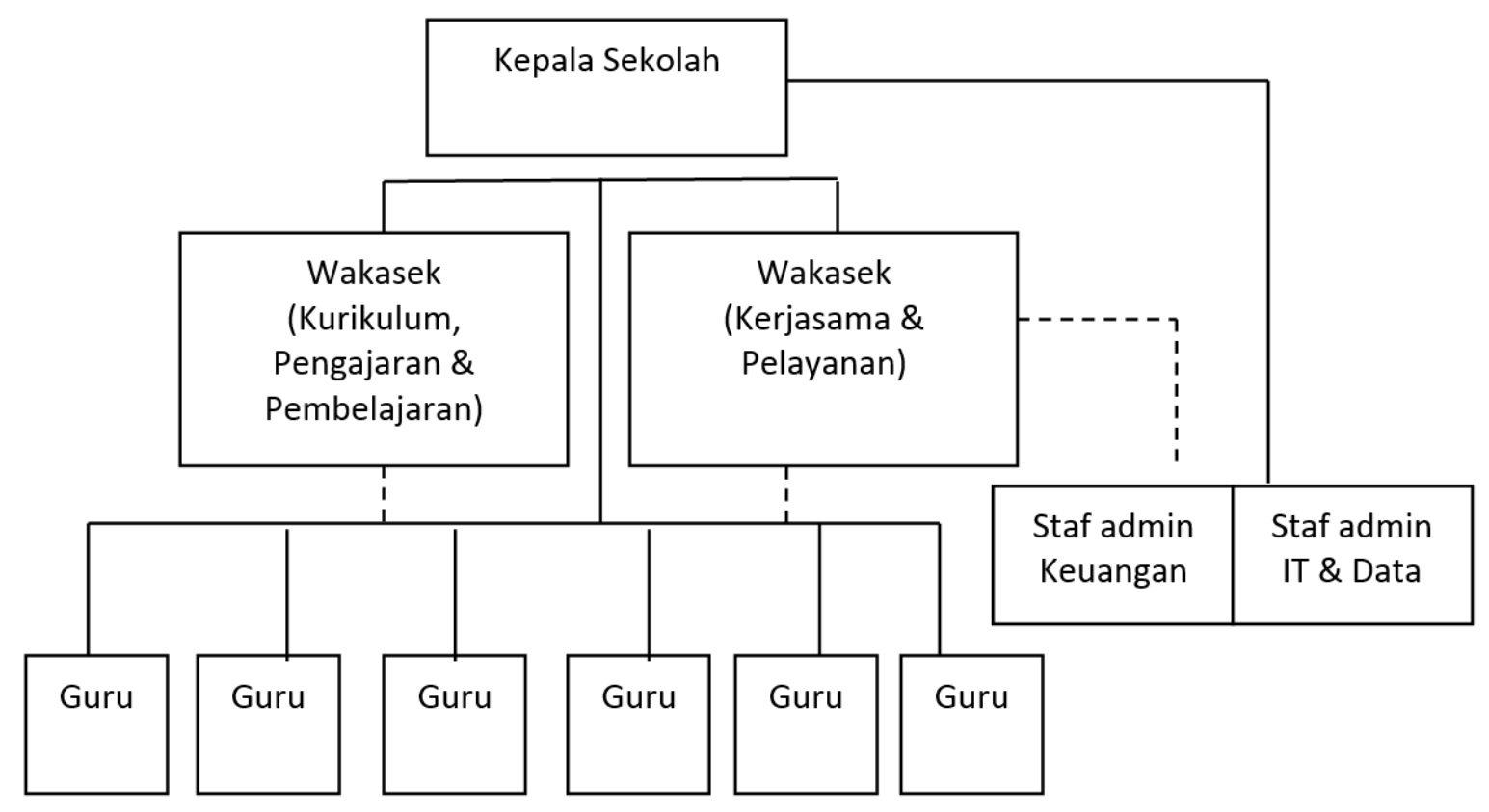

Gambar 2. Desain struktur sekolah menurut WHOT 
Tabel 2. Tugas dan Tanggungjawab dalam HPS

Komponen Tanggungjawab dalam HPS

Tugas

- Menyusun kelompok kerja HPS dengan perwakilan pemangku kepentingan di komunitas sekolah

- Mengembangkan dan melakukan riset di lingkungan

Kepala Sekolah

Organisasi, etos, dan lingkungan sekolah sekolah untuk mengidentifikasikan risiko kesehatan

- Menngunakan hasil survey untuk mengembangkan strategi guna menghilangkan atau mengurangi risiko tersebut

- Mempersiapkan dana untuk melakukan asesmen kebutuhan dan sumber daya yang dibutuhkan untuk mengimplementasikan kebijakan HPS

- Bekerja secara berkelompok untuk melakukan

$\begin{array}{ll}\text { Wakil Kepala } & \text { Kurikulum, pengajaran, dan } \\ \text { Sekolah I } & \text { pembelajaran }\end{array}$

Wakil Kepala Sekolah II
Kerjasama dan pelayanan audit kurikulum untuk memastikan konten dan isu mengenai promosi kesehatan

- Mengembangkan in-service programs pembelajaran (untuk guru) dan non guru

- Menyusun rencana dan mengimplemantasikan forum HPS untuk meningkatkan kesadaran orangtua dan komunitas, sekolah, serta merencanakan pertemuanpertemuan untuk mengimplementasikan kebijakan
Tugas dan tanggung jawab kepala sekolah dan wakil kepala sekolah seperti pada tabel 2. Konsekuensi dari struktur tersebut adalah pentingnya dilakukan pengembangan kapasitas SDM di sekolah. Bila dikaitkan dengan paparan Adelman \& Taylor (1999) dan hasil review literatur yang dilakukan oleh Liopis \& Barry (2005) maka orangorang kunci di sekolah perlu mendapatkan penguatan kapasitas. Kepala sekolah penting mendapatkan program pelatihan dan pendampingan sehingga memiliki kemampuan unruk: memahami konsep HPS dan menguraikannya dalam visi misi dan tujuan sekolah, mengidentifikasikan masalah dan merancang program, mengelola program, memonitor dan mengevaluasi program, pengalokasian anggaran; serta kerjasama dengan pemangku kepentingan. Guru, perlu ditingkatkan profesionalitasnya sehingga mampu dan terampil mengajar, mengatasi hambatan belajar, sekaligus mempromosikan kesehatan bagi siswa. Staf administratif perlu mendapatkan penguatan kapasitas dalam membantu pengelolaan anggaran yang ramah terhadap kebutuhan program kesehatan mental anak. Staf data dan teknologi informasi perlu mendapat penguatan kapasitas untuk mengelola data yang dapat diakses secara mudah dan informatif untuk mendukung keberhasilan monitoring dan evaluasi program yang dijalankan sekolah.

\section{SIMPULAN}

Masalah kesehatan mental pada anak dan remaja telah menjadi masalah global yang perlu mendapat perhatian bagi semua pihak. Untuk mengatasinya maka sekolah mendapat mandat sebagai salah satu setting promosi kesehatan mental (Health Promoting School/HPS). Mandat tersebut tidak mudah untuk dijalankan mengingat selama ini sekolah menganggap bisnis utamanya adalah pengajaran akademik. Agar sekolah mampu menjalankan tugas pengajaran sekaligus mempromosikan kesehatan maka sekolah perlu dipersiapkan secara sistematis. 
Persiapan yang perlu melibatkan perubahan pada level organisasi. Agar mencapai keberhasilan yang diharapkan maka elemen-elemen yang perlu disiapkan oleh organisasi antara lain: (1) Perubahan kebijakan sekolah yang diterjemahkan ke dalam praktik yang dilakukan per hari; (2) Perubahan sistem termasuk alokasi sumber daya dan anggaran yang dinyatakan dalam rumusan kebijakan maupun struktur organisasi yang mampu mengakomidasi dua tugas utama sekolah, yang mengatasi hambatan pembelajaran dan mempromosikan kesehatan. Mengacu pada konsep WHO mengenai HPS, maka terdapat 3 elemen saling terintegrasi yang perlu diwadahi dalam merancang struktur organisasi, yakni: (1) organisasi, etos dan lingkungan sekolah; (2) Kurikulum, pengajaran, dan pembelajaran, dan (3) kerjasama dan pelayanan. Selain itu, dalam struktur perlu dimasukkan supporting staff, terutama membantu administrasi keuangan, dan pendataan/teknologi informasi.

Dalam promosi kesehatan mental di sekolah, keberhasilannya banyak diletakkan pada operating core, yakni guru. Dengan demikian, guru-guru di sekolah yang mempromosikan kesehatan perlu mendapat penguatan kapasitas agar profesional dalam mengatasi hambatan belajar pada siswa sekaligus mempromosikan kesehatan mental, melalui kurikulum yang diuraikan dalam tindakan/ kegiatan sehari-hari di sekolah. Kepala sekolah dan wakil kepala sekolah perlu penguatan kapasitas dalam memahami konsep HPS, kemampuan mengidentifikasikan masalah dan merancang program, kemampuan dan keterampilan mengelola program, kemampuan memonitor dan mengevaluasi program, pengalokasian anggaran; serta kemampuan kerjasama dengan pemangku kepentingan.

\section{DAFTAR PUSTAKA}

Adams, C. (2007). Promotion and prevention in mental health. Community Practitioner, 80 (3), $10-15$.

Adelman, H.S., \& Taylor, L. (1999). Mental heatth in school and system restructuring. Clinical Psychology Review, 19 (2), 137-163.

Aggleton,P., Dennison,C. \& Warwick,I.(2010). Promoting health and well-being through school. New York: Routledge Falmer.

Atkinson,M. \& Hornby,G. (2002). Mental health handbook for school. London: RoutledgeFalmer.

Clarke,A.M. \& Barry,M. (2010). An evaluation of the Zippy's Friends emotional well-being program for primary school in Ireland. Diunduh dari: http://www.healtpromotion.cywhs. sa.gov.au/Content.aspx? $\mathrm{p}=154$

Cummings, T.G., \& Worley, C.G. (2008). Organizational Development and Change (9 $9^{\text {th }}$ Edition). Mason, OH: Thomson South-Western.

Dix,K.L., Slee,P.T., Lawson,M.J., \& Keeves,J.P. (2012). Implementing quality of whole-school mental health promotion and student's academic perormance. Child and Adolesent Mental Health, 17, (1), 45-51. 
Kementerian Pendidikan dan Kebudayaan (2012).Pedoman dan Pembinaan Usaha Kesehatan Sekolah.Direktorat Pendidikan Dasar: Jakarta.

Leger,L.H.(1999). The opportunities and effectiveness of the health promoting primary school in improving child health - a review of the claims and evidence. Health Education Research: Theory \& Practice, 14 (1), 51-69.

Lopis,J., \& Barry, M.M. (2005). What makes mental health promotion effectives? Promotion and Education, 2, 47 - 55.

Mintzberg, H. (1980). Structure in 5'S: A synthesis of the research on organization design. Management Science, 26 (3), 322-341.

Miller,D.N., Nickerson, A.B., \& Jimerson, S.R. (2009). Positive psikologi and school-based intervention. In Rich Gilman, E.Scott Huebner, Michael J.Furlong. Handbook of Positive Psychology in School. London: Routledge.

Notoatmodjo, S. (2010).Promosi Kesehatan: Teori dan Aplikasi.Jakarta: Rineka Cipta.

Rowling, L. (2009). Strengthening "school" in school mental health promotion. Health Education. 109 ( 4), 357 - 568.

Samdal, O., Rowling, L.(2010). Theoretical and empirical base for implementation components of health-promoting schools. Health Education, 111(5), 367-390.

Spotlight. (2012). Well-being: Promoting mental health in schools. OireachtasLibrary \& Research Service. Bulletin, 2.

Weare, K. (2010). Promoting mental health through school, dalam Promoting Health and Well-being Through School, diedit oleh Petter Aggeton, Catherine Dennison, \& Ian Warwick, London \& New York: Routlegde

Williams,S.M., Saxena, S., \& McQueen, D.V. (2005). The Momentum for mental health promotion. Promotion and Education, 2, 6-8.

World Health Organization (1998). Health Promoting School. Diunduh dari http://www.who. int/school_youth_health/media/en/92.pdf.

World Health Organization (2003). Investing in Mental Health. Genewa. World Heatlh Organization.

World Health Organization. (2013). Mental Health Action Plan 2013-2020. World Health Organization. Diunduh dari http://www.who.int/mental_health/publications/action_ plan/en/

Weare, K. (2010). Promoting mental health through school, dalam Promoting Health and Well-being Through School, diedit oleh Petter Aggeton, Catherine Dennison, \& Ian Warwick, London \& New York: Routlegde

World Health Organization (2004). Preventive of mental disorder: Effective intervention and policy options, Summary Report. Diunduh dari http://www.who.int/mental_health/ evidence/an/prevention_of_mental disorder_sr.pdf. 
World Health Organization (2005). Promoting mental health: concepts, emerging evidence, practice: A Report of the World Health Organization,Department of Mental Health and Substance Abuse in collaboration with the Victorian Health Promotion Foundation and The University of Melbourne. Diunduh dari http://www.who.int/mental_health/ evidence/MH_Promotion_Book.pdf

Wyn, J., Cahill, H., Holdsworth., Rowling, L., \& Carson, S. (2000). MindMatters, a whole school approach promoting mental health and well-being. Australian and New Zealand Journal of Psychiactry, 34 (594-601) 